\title{
Nutrition policy process challenges in Iran
}

\author{
Massomeh Goshtaei ${ }^{1}$, Hamid Ravaghi ${ }^{2}$, Ali Akbari Sari ${ }^{1}$, Zahra Abdollahi ${ }^{3}$
}

${ }^{1}$ Department of Health Management and Economics, School of Public Health, Tehran University of Medical Sciences, Tehran, Iran

${ }^{2}$ Department of Health Services Management, Health Management and Economics Research Centre, School of Health Management and Information Sciences, Iran University of Medical Sciences, Tehran, Iran

${ }^{3}$ Nutrition Department, Ministry of Health and Medical Education, Tehran, Iran

\section{Type of article: Original}

\begin{abstract}
Introduction: Nutrition transition is occurring rapidly in the world, especially in developing countries. The nutrition transition occurred in Iran very fast due to urbanization and changes in the lifestyle of people, leading to overweight and obesity. However, nutritional deficiencies are still detected due to economic factors and low nutritional knowledge. Nutrition policies do not adequately respond to the nutrition challenges in Iran. This study was conducted to evaluate and analyze the nutrition policy process challenges in Iran.

Methods: A qualitative study using semi-structured interviews was conducted with 59 policy makers and nutrition experts of medical universities across Iran. Interviews were continued until data saturation was achieved. Data were supplemented with surveys and documentary analysis. Thematic analysis was guided by the propositions of the stages heuristic framework.

Results: The results were categorized into four main themes and eight sub-themes. The main themes were 1) nutrition problem definition, 2) policy formulation, 3) implementation of the policies, and 4) evaluation of the policies. However, the multi-faceted nature of the nutritional problem makes it difficult to deal with, so a multisectoral approach is needed.

Conclusion: Nutrition policies have been implemented in Iran with varying degrees of success and with different levels of cross-sectoral collaboration. The nutrition policies sometimes have not been able to respond to the nutritional problems. One of the important reasons is that nutrition is not a priority for policy makers. Many policies suffer from a lack of adequate and appropriate resource allocation. Cooperation mechanisms to resolve nutritional problems are sometimes ineffective and inefficient.
\end{abstract}

Keywords: nutrition policy challenges, nutrition analysis, health policy process analysis, stages heuristic

\section{Introduction}

\subsection{Background and study logic}

Nutrition is a foundation for economic and social development. Considering the primary effects of nutrition on the health and neurodevelopment of children, improvement of the nutritional status has direct impacts on the objectives of the millennium development (1). Nutrition transition is occurring rapidly in the world, especially in developing countries. It started in the last two decades of the $20^{\text {th }}$ century (2). Nutrition transition is a period when changes occur in the dietary pattern and physical activity; the diet of the people is full of saturated fat, sugar, and refined foods and rather lacks fiber, resulting in excess weight, obesity, and associated diseases $(2,3)$. These countries have high levels of overweight and obese people, and there are moderate levels of malnutrition and micronutrient deficiencies. It seems that the nutrition transition occurred very rapidly in Iran due to urbanization and changes in the population, lifestyle, and culture of the Iranian people, leading to overweight people and obesity $(4,5)$. However,

\section{Corresponding author:}

Hamid Ravaghi, Department of Health Services Management, Health Management and Economics Research Centre, School of Health Management and Information Sciences, Iran University of Medical Sciences, Tehran, Iran.

Tel: +98.9123505072, Fax: +98.2133909991, E-mail: ravaghih@gmail.com

Received: November 21, 2015, Accepted: December 29, 2015, Published: February 2016

iThenticate screening: December 29, 2015, English editing: January 14, 2016, Quality control: February 03, 2016

(C) 2016 The Authors. This is an open access article under the terms of the Creative Commons Attribution-NonCommercialNoDerivs License, which permits use and distribution in any medium, provided the original work is properly cited, the use is non-commercial and no modifications or adaptations are made. 
nutritional deficiencies are still detected due to economic factors and low nutritional knowledge. Nutritional policies play a major role in the improvement of the health status of the society. The analysis of these policies can help to design and implement interventions and plans to improve the nutritional status of the society, especially the lowincome population. In Iran, numerous nutritional policies have been established, but no systematic research has been conducted to analyze and evaluate these policies with policy analysis frameworks. Understanding the challenges in nutrition policy and program provides support for the most important needs and the areas where they will be effective. In this study, we systematically applied an analytical framework to better understand the challenges of processes of nutrition policy in Iran. Analysis of the policy process is complex, but there are frameworks and models that simplify it $(6,7)$. One of the most common frameworks used for health policy analysis is the health policy triangle framework $(6,8)$. It consists of four components, i.e., process, context, actors, and content. One of the important components of this framework is the policy-making process. The Policy Process states the way in which policies are initiated, developed or formulated, negotiated, communicated, implemented, and evaluated. The policy cycle or stages approach is one of the ongoing ways of exploring the policy process (9, 10). The most common approach to understanding policy processes is the 'stages heuristic' $(11,12)$. What this means is breaking down the policy process into a series of stages. It has four stages, i.e., problem identification and issue recognition, policy formulation, policy implementation, and policy evaluation (13). The heuristic offers a useful and simple framework of thinking about the entire public policy process, and it helps researchers plan their research within a wider framework (6) with respect to its limitations. There are limitations to using this framework. First, it looks as if the policy process is linear; it proceeds easily from one stage to another, from problem recognition to implementation and evaluation. However, the process is seldom that clear. It may be at the stage of implementation that problem recognition occurs or policies may be formulated but never reach implementation. In other words, policy making is seldom a rational process, because it is affected by different interests (8).

\subsection{Objectives}

The general objective of this research was to determine nutrition policy process challenges in Iran. The specific objectives were to identify the challenges of problem definition, nutrition policy formulation, implementation, and evaluation by using the stages heuristic approach.

\section{Material and Methods}

This was qualitative research. Purposive sampling was used to identify the key informants. This study was approved in by the Ethics Committee of Tehran University of Medical Sciences (TUMS) by code of 8921557005. Policy makers and stakeholders were identified with the help of the Nutrition Department at the Ministry of Health. Semistructured interviews were conducted with 59 policy makers, well-informed key stakeholders, and nutrition experts at medical universities across Iran. The interviews with 23 policy makers were conducted in a face-to-face manner. Open-ended questions accompanied by a letter from the Ministry of Health were sent to 58 nutrition offices of medical universities in different provinces. Out of 58 questionnaires, 36 people responded by email. The characteristics of the interviewees are presented in Table 1.

Table 1. Characteristics of the interviewees

\begin{tabular}{|l|l|l|}
\hline Variables & $\mathrm{n}$ \\
\hline Education level & Ph.D. and other Doctoral Degree & 11 \\
\cline { 2 - 3 } & Master's Degree & 10 \\
\cline { 2 - 3 } & Bachelor's Degree & 38 \\
\hline \multirow{5}{*}{ Work experience } & Less than 10 years & 12 \\
\cline { 2 - 3 } & 10-20 years & 35 \\
\cline { 2 - 3 } & More than 20 years & 12 \\
\hline Position & Nutrition expert & 36 \\
\cline { 2 - 3 } & Member of parliament & 1 \\
\cline { 2 - 3 } & General director of MOH & 1 \\
\cline { 2 - 3 } & Ministry expert & 6 \\
\hline & Manager of other ministries & 3 \\
\hline & Expert of other ministries & 8 \\
\hline & Faculty member & 4 \\
\hline
\end{tabular}


Before conducting the interviews, a topic guide was developed with the help of the experts. The topic guide was piloted through five interviews, and some required amendments were made. The questions that were designed for policy makers and stakeholders were slightly different from the questions prepared for the health staff in nutrition offices. The interviews were conducted by the researcher in a face-to-face manner over a period of 12 months. The participants signed informed consent forms before participating in the study. The average length of the interviews was 55 minutes, and they were continued until data saturation was reached. Thematic analysis was conducted (14). The data from the interviews were supplemented and supported by the analysis of national reports, surveys, minutes of meetings, government documents, and published articles. The data on the nutrition policy process were gathered mainly in the MOPH's departments and other government agencies. The methods of evaluating the validity and reliability of qualitative studies were employed to assess the validity and reliability of the findings. Credibility, conformability, transferability, and dependability are the essential criteria for assessing the validity and reliability of qualitative research $(15,16)$. To ensure credibility, member checks and data saturation were used. For member checking, the interviews were transcribed verbatim, and the transcripts were forwarded to the interviewees via email; the interviewees were requested to notify the research team of any changes that seemed necessary. Conformability was considered through an inquiry trail. An inquiry trail includes an assessment of the data and supporting documents by an external reviewer (17). In this study, transferability was addressed by conducting interviews with different participants, providing direct quotes of the interview data and rich descriptions of design and findings of the study. Dependability refers to reliability of data $(15,17)$. To achieve dependability, two researchers independently read and coded the transcripts of the interviews. They compared their codes, discussed discrepancies, and revised them until consensus was reached.

To check the reliability of the e-mail responses, the respondents were contacted via email and telephone. Also, responses to letters that were emailed were checked informally with the participants for accuracy during data collection. However, there were no significant difference between e-mail responses and the responses produced by the interviews (18). Triangulation was used to investigate the validity of the data (19). For triangulation, the results were compared against the available evidence and guidelines. As for reflexivity, the researcher was an independent person who tried to maintain a neutral position during the interviews and acquisition of the data. Thematic analysis was used for the data, and it was considered suitable for informing policy development (20). MAXQDA 10 software was used for data coding and management (21). The stages model was used to refine the codes and explore relationships between themes. According to a suggestion made by Walt, theoretical models do not imply an approach to analysis but rather provide consistency and potential avenues for linking themes and concepts (6). The results were categorized into four themes and eight sub-themes according to the stages heuristic approach (10).

\section{Results}

\subsection{Problem definition}

Problem definition explores how subjects get on the policy agenda and why some subjects do not even get discussed (8). Iran is facing problems of undernutrition and the burden of overweight. Many respondents indicated that the key nutrition challenges are malnutrition, micronutrient deficiencies, obesity, and non-communicable diseases. According to some interviewees, a situation analysis should be performed first, and then decisions should be made, with interventions being designed according to the available data and information. In 2010, the national food security monitoring system was initiated, and a map showing the food-vulnerable regions in the country was prepared. The map served as an introduction to the preparation of the national nutrition policy statement by the Ministry of Health.

3.1.1. Challenges of nutrition problem definition (Table 2)

Interviews and documentary analysis showed that the nutritional problems are not clearly defined. Some interviewees stated that policy process rarely goes on from the identification of a problem to looking for solutions. Policy makers presented that contextual factors have an effect on the nutritional problem: "Rapid urbanization causes damage to the agricultural sector, and increases poor areas in the cities." As a result, demographic changes can have a direct impact on nutritional status, and policy makers may not give these changes and their impacts enough attention. Many policy makers recognized the problems, but they stated that senior policy makers were not aware of the nutrition problem or were giving it inadequate attention. According to some interviewees, nutritional problems receive attention only when policy makers become sensitive to them, and this requires negotiations to achieve their support. The media are important for drawing attention to issues and making governments act, but they give healthy nutrition very little attention. Then reason for this is that there is a conflict of interest, such as revenue acquired from advertising unhealthy foods. Also advocacy, lobbying, and negotiation are weak in nutrition policy. It seems this problem can be due to the facts that stewardship and leadership are fragmented in the field of nutrition 
policy. Micronutrient studies are conducted only every 10 years, so it is difficult to analyze the status of micronutrients and identify trends. One of the interviewees stated that there is no coordination in nutrition policy making. Sometimes organizations have inverted policies. For example, the Food and Drug Administration approved some food products that are unhealthy. Moreover, nutrition policies in the country are fraught with multiplicity. The result is that, with rising prices for meat and dairy commodities, these valuable foods have been replaced in the food baskets of low-income households by high-calorie food.

Table 2. Summary of the challenges of the nutrition policy process in Iran

\begin{tabular}{|c|c|}
\hline $\begin{array}{l}\text { Stages of } \\
\text { policy process }\end{array}$ & Challenges \\
\hline \multirow{5}{*}{$\begin{array}{l}\text { Problem } \\
\text { identification }\end{array}$} & Nutrition policies do not adequately respond to the nutrition problems. \\
\hline & Senior policy makers are not aware of the nutrition problem. \\
\hline & Sometimes nutritional problems are not clear. \\
\hline & $\begin{array}{l}\text { The quantity and quality of research in nutrition problems are low and sometimes are not } \\
\text { updated. }\end{array}$ \\
\hline & $\begin{array}{l}\text { The multifaceted nature of the nutritional problem makes it difficult to deal with, and the multi- } \\
\text { sectoral approach is needed. }\end{array}$ \\
\hline \multirow{6}{*}{$\begin{array}{l}\text { Policy } \\
\text { formulation }\end{array}$} & Iran has inadequate coordination mechanisms to solve existing nutrition challenges. \\
\hline & Nutrition policies often do not include evidence-based interventions. \\
\hline & Diversity and fragmentation of nutrition policy formulation are demonstrated. \\
\hline & There is not adequate support of policy-makers of nutrition programs. \\
\hline & Negotiation and advocacy in nutrition policy are poor. \\
\hline & $\begin{array}{l}\text { The weakness of agreement within the core policy community on the priority and sequencing } \\
\text { of interventions and on institutional roles and responsibilities is a problem. }\end{array}$ \\
\hline \multirow{7}{*}{$\begin{array}{l}\text { Policy } \\
\text { Implementation }\end{array}$} & The nutrition policy making process is a top-down approach in Iran \\
\hline & $\begin{array}{l}\text { Limited resources, including money, time, human resources, and staff motivation, impair } \\
\text { progress. }\end{array}$ \\
\hline & $\begin{array}{l}\text { There are often discrepancies between policies at the national level and programs being } \\
\text { implemented at the provincial or district level. }\end{array}$ \\
\hline & $\begin{array}{l}\text { National capacity in public health nutrition is limited, especially human resources for } \\
\text { implementing nutrition programs. }\end{array}$ \\
\hline & Some policies do not clearly indicate operational plans and programs of work. \\
\hline & Fragmented coordination impedes policy implementation. \\
\hline & $\begin{array}{l}\text { Functional overlap in leadership, governance, and supervision of the nutrition program slows } \\
\text { progress. }\end{array}$ \\
\hline \multirow{4}{*}{$\begin{array}{l}\text { Policy } \\
\text { evaluation }\end{array}$} & National surveys do not adequately show the nutrition indicators and success of programs. \\
\hline & There is not an adequate nutrition surveillance system in Iran. \\
\hline & The impacts of most programs and policies are not evaluated systematically. \\
\hline & Evaluation of nutrition policy is expensive and takes a long time. \\
\hline
\end{tabular}

\subsection{Policy formulation}

Policy formulation explores who is involved in formulating policy, how policies are arrived at, agreed upon, and communicated (8).

3.2.1. National nutrition policy statement

A national nutrition policy statement was brought to the High Council of Health and Food Security, but it was not approved by the council because the council authorities had been changed, and it was not sent to other organizations for execution. The Minister of Health and Medical Education signed the statement and sent it the medical universities in the country, and the university deans were obligated to execute it through the Provincial Health Council. The interviewees had diverse opinions about the national nutrition policy statement. The participants from the Ministry of Health mostly had positive views about it, while other participants from other organizations believed that the Ministry of Health could not successfully implement national nutrition policy statement alone. According to these interviews, it should be implemented in a centralized manner, which is beyond the capability of one organization. 


\subsubsection{Challenges of nutrition policy formulation}

Documents and interviews indicated that the lack of appropriate structures in the Department of Nutrition in the Ministry of Health is a problem for nutrition policy. Also, the shortage of capable human resources was recognized as a problem for the formulation of appropriate nutrition policy. There is an incomplete and shallow relationship between academics and executors. However, many interviewees believed that the process of nutrition policy making is not evidence-based, and the problems become policies when negotiations and social pressure are used for advocacy of policy makers. Documents and interviews showed that there also are many challenges to nutrition policy formulation, including measuring the levels of resources and reconciling the values, beliefs, and power of diverse actors.

\subsubsection{Participation of the Stakeholders}

There are many different stakeholders with different power who are involved, or would like to be involved, in nutrition policy processes. Coordination mechanisms for nutrition were located in the Ministry of Health. Although the participation of most of the stakeholders was requested at the meeting of the High Council of Health and Food Security, many senior managers are often absent in these meetings. Moreover, many organizations do not regard health concerns in their decisions. According to some interviewees, with regards to the multi-sectoral nature of nutrition policy making, many stakeholders still do not consider healthy nutrition as one of the prerequisites of their programs: "There is no health perspective in other organizations; for example, when the prices increase, the Ministry of Health issues an order to stop or reverse the situation, but nobody cares that some harmful products are imported." The public, and in particular the target population, were rarely involved directly in the nutrition policy processes.

3.2.4. Challenges of national nutrition policy statement preparation

Lack of some senior policy makers in preparing the national nutrition policy statement was one of the challenges. Many organizations sent their employee when the national nutrition policy statement was being prepared, and senior managers were absent, which resulted in the lack of the commitment of the organization to the national nutrition policy statement. The representatives of the organizations constantly changed in meetings. Another major challenge was that the national nutrition policy statement was not signed by the president. Therefore, some organizations have not committed themselves to implement it.

\subsection{Policy implementation}

Implementation is process of turning a policy into practice (8).

3.3.1. Challenges of nutrition policy implementation

Some nutrition experts presented the health policy making process as a top-down approach in Iran. They said that the policies are set at higher levels in a political process, and then they are communicated to lower levels. "Universities are not invited in the nutrition policy making meeting." Implementation challenges are often related to limited resources, including money, time, and human resources, as well as staff motivation. The human resource capacity for public health nutrition is insufficient, but, according to some interviewees, the greatest challenge for implementation of nutrition policy is the complexity of cross-sectoral collaboration. Many of key informants stated that sometimes action plans, guidelines, and indicators are not clear. Also, some indicators were not defined properly. Policy makers stated that nutrition programs and policies faced major challenges, including the shortage of manpower. Financial limitations were also referred to as another executive problem for policy making. A number of policy makers mentioned the structural and administrative problems of the nutrition departments and nutrition units in the universities as serious problems. According to many interviewees, one of the problems in the field of nutrition is that the Deputy of Management and Resource Development pay not enough attention to the administration, structure, and the job description of the nutrition experts of the universities. This problem has not been resolved despite the efforts of the nutrition department of $\mathrm{MOH}$, and the nutrition units of the universities are parts of other departments, such as the Reproductive Health Department, which is one of the challenges in nutritional programs and interventions. Participants from the Ministry of Health and universities mentioned that they could finally station nutrition experts in the universities and health centers, but there were no nutrition experts in the environmental levels. However, this issue has been taken care of in the health system reform project, and it is expected that nutrition experts will be available in urban health centers. Some interviewees believed that another problem for implementing nutritional policies is the executive limitations of the national capacities. Shortage of human resources and incomplete education of the health staff are other problems in executing the policies. Documents presented that attitudes, strategies, and knowledge of health workers are informally constructed and influence policy implementation. Some interviewees stated that, in most programs, the requirements of the establishment of the program, the division of work, preparation of experts, and a deployment method is unclear at the national and provincial levels. 


\subsubsection{Collaboration and commitment}

According to the interviewees, nutritional interventions require collaboration among different sectors. Therefore, lack of collaboration among different sectors is an important issue that has not been dealt with effectively. Moreover, some organizations do not see themselves as responsible and accountable for executing nutritional policies. One of the interviewees stated that attention to nutritional programs without considering other factors related to health resulted in wasting the resources. Some stakeholders expressed that there are weaknesses in the collaboration, planning, and decision making structures and processes at each level (regional and national) and in the vertical collaboration among these levels. Therefore, the advocacy for nutrition at the regional levels has been effective in raising local awareness about nutrition, but the staffs at these levels do not have the knowledge and skills required to design and implement interventions in different sectors. The interviewees talked about the identification of vulnerable populations and provision of their food requirements. In their opinion, the methods that the government uses to meet the nutritional needs of the society have flaws, and many subsidies in this regard have been spent elsewhere. Some interviewees stated that different institutes were responsible for policy making in the field of nutrition and emphasized that nutrition policy is multi-sectoral. Moreover, they believed that the duties of the institutions regarding nutrition and food security have been changing regularly. The Environmental and Occupational Health Center and the Food and Drug Administration have functional overlaps in leadership, governance, and supervision of the nutrition program. It causes interference with the policies and programs.

\subsection{Evaluation of the Policies}

This evaluation identifies what happens after a policy is put into effect, i.e., how it is monitored, whether it achieves its objectives, and whether it has unintended consequences (8). A National Food and Nutrition Surveillance System were conducted in six provinces in Iran. Through this surveillance system, seasonal children's vitamin D status, anthropometric status, and oil intake are measured periodically. The findings of this system provide the basis for monitoring and evaluation of the national programs.

\subsubsection{Challenges of evaluation of nutrition policies}

The nutrition surveillance system is an essential instrument for the detection of nutrition and nutrition-related health problems for program evaluation, but there is not an adequate nutrition surveillance system in Iran. It is in the primary stage. However, many interviewees were of the opinion that evaluation of the policies and interventions did not receive appropriate attention. Some interviewees believed that the results of surveys and research were not used appropriately. Also, some nutrition policies do not have clear indicators. Iran has conducted national surveys and evaluated programs, but some indicators did not provide the information necessary for monitoring nutrition policy or the effects of the intervention programs that were being implemented. "Survey in our country is a kind of trouble for the executive team and they take it as an insult. If they regard it as a tool to enhance their activities, they give more credit to it." Evaluations of nutrition intervention outcomes, without ties to well-funded research studies, are rare; thus, policymakers are often left without strong and current evidence of the effectiveness of their policies.

\section{Discussion}

It seems that several major changes in Iran have resulted in a distinct change in the structure of the diet and household food basket, including decreased fertility and aging population, rapid migration to cities, and epidemiologic transition. The rapid migration occurred in recent years, but it is not necessarily equal to development and has increased urban poverty. Moreover, it has caused damage to agriculture and increased marginalization of cities. Urbanization has changed dietary habits and patterns as well. Urban diets contain more fat and sugar and less fiber. As a result, population changes can have a direct effect on the nutritional status. A study by Costas et al. in 2004 found that migration to cities in developing countries had a negative impact on food production, distribution, and availability (22). Considering the fact that after executing the target subsidies law, the low income population of the society has become more vulnerable in terms of well-being and especially nutrition due to the resulting inflation and terminating the low-priced food compensation policies. According to the second article of the target subsidies law the effects of implementing this program on the well-being of the society should be considered. Also the costs of the ill effects of economic plan and policies on nutrition should be compensated from the very same resources of implementing the economic plans and policies. However, so far, the nutritional policies have failed to meet the nutritional problems of the country. The trend of obesity is increasing rapidly. A study by Esteghamati et al. showed that the mean BMI had an increasing trend in Iran in recent years (23). We are now facing an increase in noncommunicable diseases, which mainly results from obesity and nutrition (24). However, there is a micronutrient deficiency in the country. This double burden of nutritional disorders is encountered by many developing countries (25). A study by Prentice et al. showed that developing countries face a rapid increase in non-communicable 
diseases due to problems related to infectious diseases and nutrient deficiency (26), which lead to complicated nutritional problems in these countries. One of the main reasons for this problem is that nutrition is not a priority for policy makers, maybe due to the following items:

1) Nutritional problems are not apparent and may manifest years later, such as vitamin D deficiency.

2) Many people with malnutrition belong to poor and financially weak levels of the society.

3) Many nutrition policy makers are influential people and have limited power.

4) Researchers and academics have performed few studies and socioeconomic analyses on nutrition, which has led to the inattention of the policy makers to this issue.

5) Most policy makers have a clinical point of view towards nutrition and less attention is paid to prevention and the social aspects of nutrition.

Many policies lack a definite action plan, timetable, and financial resources. However, financial problems are also seen in European countries as well. In a study by the WHO in 2009, shortage of financial resources and inadequate cooperation were the major obstacles to implementing nutritional policies in Europe (27). These items seem to exist in most countries as the challenges of the health system policies. Cooperative mechanisms for resolving nutritional problems are mostly ineffective in Iran. Nutritional policies cannot be successful without the collaboration and cooperation of other institutions and organizations, such as the Ministry of Economic Affairs and Finance, the Ministry of Education, and the Ministry of Agriculture. These inconsistencies, which are even observed between the areas of education and health, jeopardize many nutritional policies. The curricula in the fields of nutrition and medical sciences are mostly clinical-oriented, and the graduates are not capable of solving the nutritional problems of the society. Also, health workers need more than just different orientations; they need additional skills for building on the experience of alliances and lobbying (28). Nutrition policy making in Iran is mostly top down and performed at high levels of policy making, while lower executive levels have a weak role in preparing the policies, which may be due to the need for the participation of other organizations and financial resources. The results of this study showed that many nutrition policies and programs in Iran lack definite and clear indicators for evaluation purposes. Moreover, the national and regional capacities for the execution of the policies are not identified. The evaluation of nutrition policy is expensive and requires a long time. However, surveys are needed to evaluate the nutrition programs. Using of health policy models in this study could help systematically analyze the nutrition policy process. Stages heuristic framework helped to better understand the challenges of the nutrition policy process in this study. Policy analysis in low- and middle-income countries remains in the primary stage (29). Also, there is little use of analytical models for health programs and policy in low and middle income countries (30). The policy stages help disaggregate these complex phenomena into a series of events (31), but nutrition policy processes have a continuous nature, often resulting in policy decisions being prolonged over periods of several years; therefore, it is difficult to divide it into stages. However, this study showed that the stages model focused on various parts of policy processes and classified the policy process.

\section{Conclusions}

In this study, the stages heuristic framework was applied systematically to better understand the nutrition policy process in Iran. The four stages are problem definition, policy formulation, policy implementation, and evaluation. Different studies have confirmed the role of nutrition in the health, learning, and efficacy of people, and its relationship with economic development is well-established. This study presented the gap between what is known and what is in the work related to nutrition policy in Iran. According to the research conducted by nutrition institutes and health authorities, the work to be done includes nutrition policies, preparation of appropriate supportive regulation, attention to vulnerable regions and populations, and regulation and control of the price of food products. These activities will provide families with opportunities to have healthy nutrition.

\section{Acknowledgments:}

This study was part of a $\mathrm{PhD}$ thesis supported by Tehran University of Medical Sciences. The authors thank the members of the Nutrition Department at the Ministry of Health and Medical Education for their assistance in all steps of the data collection process.

\section{Conflict of Interest:}

There is no conflict of interest to be declared.

\section{Authors' contributions:}

All authors contributed to this project and article equally. All authors read and approved the final manuscript. 


\section{References}

1) De Onis M, Brown D, Blossner M, Borghi E. Levels and trends in child malnutrition. UNICEF-WHO-The World Bank joint child malnutrition estimates. 2012.

2) Popkin BM, Gordon-Larsen P. The nutrition transition: worldwide obesity dynamics and their determinants. Int J Obes Relat Metab Disord. 2004; 28 Suppl 3: S2-9. doi: 10.1038/sj.ijo.0802804, PMID: 15543214.

3) Popkin BM. The nutrition transition: an overview of world patterns of change. Nutr Rev. 2004; 62(7 Pt 2): S140-3. doi: 10.1111/j.1753-4887.2004.tb00084, PMID: 15387480.

4) Kelishadi R, Alikhani S, Delavari A, Alaedini F, Safaie A, Hojatzadeh E. Obesity and associated lifestyle behaviours in Iran: findings from the first national non-communicable disease risk factor surveillance survey. Public Health Nutr. 2008; 11(03): 246-51. doi: 10.1017/S1368980007000262, PMID: 17625028.

5) Popkin BM. The shift in stages of the nutrition transition in the developing world differs from past experiences! Public health nutrition. 2002; 5(1A): 205-14, PMID: 12027286

6) Walt G, Shiffman J, Schneider H, Murray SF, Brugha R, Gilson L. 'Doing' health policy analysis: methodological and conceptual reflections and challenges. Health Policy Plan. 2008; 23(5): 308-17. doi: 10.1093/heapol/czn024, PMID: 18701552, PMCID: PMC2515406.

7) Collins T. Health policy analysis: a simple tool for policy makers. Public Health. 2005; 119(3): 192-6. doi: 10.1016/j.puhe.2004.03.006, PMID: 15661129.

8) Buse K, Mays N, Walt G. Making health policy: McGraw-Hill Education (UK); 2012.

9) Walt G, Gilson L. Can frameworks inform knowledge about health policy processes? Reviewing health policy papers on agenda setting and testing them against a specific priority-setting framework. Health Policy Plan. 2014; 29 Suppl 3: iii6-22. doi: 10.1093/heapol/czu081, PMID: 25435537.

10) Breton E, De Leeuw E. Theories of the policy process in health promotion research: a review. Health Promot Int. 2011; 26(1): 82-90. doi: 10.1093/heapro/daq051, PMID: 20719803.

11) Walt G, Feingold E. Health Policy: An Introduction to Process and Power. Journal of Public Health Policy. 1995; 16(4): 506-8. doi: 10.2307/3342629.

12) Sabatier PA, Sabatier P, Jenkins - Smith H. Policy change over a decade or more: PA; 1993.

13) Green A, Gerein N, Mirzoev T, Bird P, Pearson S, Martineau T, et al. Health policy processes in maternal health: a comparison of Vietnam, India and China. Health Policy. 2011; 100(2): 167-73. doi: 10.1016/j.healthpol.2010.11.016, PMID: 21194780.

14) Attride-Stirling J. Thematic networks: an analytic tool for qualitative research. Qualitative research. 2001; 1(3): 385-405. doi: 10.1177/146879410100100307.

15) Polit DF, Beck CT. Nursing research: Generating and assessing evidence for nursing practice: Lippincott Williams \& Wilkins; 2008.

16) Silverman D. Qualitative research: Sage; 2010.

17) Mays N, Pope C. Qualitative research in health care: Assessing quality in qualitative research. BMJ. 2000; 320(7226): 50. doi: 10.1136/bmj.320.7226.50, PMID: 10617534, PMCID: PMC1117321.

18) Meho LI. E - mail interviewing in qualitative research: A methodological discussion.. J Assoc Inf Sci Technol. 2006; 57(10): 1284-95. doi: 10.1002/asi.20416.

19) Cho J, Trent A. Validity in qualitative research revisited. Qualitative research. 2006; 6(3): 319-40. doi: $10.1177 / 1468794106065006$.

20) Braun V, Clarke V. Using thematic analysis in psychology. Qualitative research in psychology. 2006; 3(2): 77-101. doi: 10.1191/1478088706qp063oa.

21) MAXQDA P. 10.(1989-2013). MAXQDA, software for qualitative data analysis.(Version 10). Berlin, Germany: VERBI Software-Consult-Sozialforschung GmbH.

22) Stamoulis KG, Pingali P, Shetty P. Emerging challenges for food and nutrition policy in developing countries. Electronic Journal of Agricultural and Development Economics. 2004; 1(2): 154-67.

23) Esteghamati A, Khalilzadeh O, Mohammad K, Meysamie A, Rashidi A, Kamgar M, et al. Secular trends of obesity in Iran between 1999 and 2007: National Surveys of Risk Factors of Non-communicable Diseases. Metab Syndr Relat Disord. 2010; 8(3): 209-13. doi: 10.1089/met.2009.0064, PMID: 20085488.

24) Kelishadi R. Childhood overweight, obesity, and the metabolic syndrome in developing countries. Epidemiol Rev. 2007; 29(1): 62-76. doi: 10.1093/epirev/mxm003, PMID: 17478440.

25) Boutayeb A. The double burden of communicable and non-communicable diseases in developing countries. Trans R Soc Trop Med Hyg. 2006; 100(3): 191-9. doi: 10.1016/j.trstmh.2005.07.021, PMID: 16274715. 
26) Prentice AM. The emerging epidemic of obesity in developing countries. Int J Epidemiol. 2006; 35(1): 93 9. doi: 10.1093/ije/dyi272, PMID: 16326822.

27) Trübswasser U, Branca F. Nutrition policy is taking shape in Europe. Public health nutrition. 2009; 12(03): 295-306. doi: 10.1017/S1368980009004753

28) Caraher M, Coveney J. Public health nutrition and food policy. Public health nutrition. 2004; 7(05): 591-8. doi: 10.1079/PHN2003575.

29) Gilson L, Raphaely N. The terrain of health policy analysis in low and middle income countries: a review of published literature 1994-2007. Health Policy Plan. 2008; 23(5): 294-307. doi: 10.1093/heapol/czn019.

30) Walt G, Gilson L. Reforming the health sector in developing countries: the central role of policy analysis. Health Policy Plan. 1994; 9(4): 353-70. doi: 10.1093/heapol/9.4.353.

31) Tantivess S, Walt G. The role of state and non-state actors in the policy process: the contribution of policy networks to the scale-up of antiretroviral therapy in Thailand. Health Policy Plan. 2008; 23(5): 328-38. doi: 10.1093/heapol/czn023, PMID: 18658197. 